\title{
Correlation between Pupil Size and Subjective Passage of Time in Non-Human Primates
}

\author{
Tomoki W. Suzuki, ${ }^{1}$ Jun Kunimatsu, ${ }^{1,2}$ and Masaki Tanaka ${ }^{1}$ \\ ${ }^{1}$ Department of Physiology, Hokkaido University School of Medicine, Sapporo 060-8638, Japan, and ${ }^{2}$ Laboratory of Sensorimotor Research, National Eye \\ Institute, National Institutes of Health, Bethesda, Maryland 20892
}

Our daily experience of time is strongly influenced by internal states, such as arousal, attention, and mood. However, the underlying neuronal mechanism remains largely unknown. To investigate this, we recorded pupil diameter, which is closely linked to internal factors and neuromodulatory signaling, in monkeys performing the oculomotor version of the time production paradigm. In the self-timed saccade task, animals were required to make a memory-guided saccade during a predetermined time interval following a visual cue. We found that pupil diameter was negatively correlated with trial-by-trial latency of self-timed saccades. Because no significant correlation was found for visually guided saccades, correlation of self-timed saccades could not be explained solely by the facilitation of saccade execution. As the reward amount was manipulated, pupil diameter and saccade latency altered in opposite directions and the magnitudes of modulation correlated strongly across sessions, further supporting the close link between pupil diameter and the subjective passage of time. When the animals were trained to produce two different intervals depending on the instruction, the pupil size again correlated with the trial-by-trial variation of saccade latency in each condition; however, pupil diameter differed significantly for saccades with similar latencies generated under different conditions. Our results indicate that internal brain states indexed by pupil diameter, which parallel noradrenergic neuronal activity (Aston-Jones and Cohen, 2005), may bias trial-by-trial variation in the subjective passage of time.

Key words: eye movements; monkeys; pupil diameter; self-timing; temporal processing

\section{Significance Statement}

Daily experience of time is strongly influenced by our internal state, but the underlying neuronal mechanism remains elusive. Here we demonstrate that pupil diameter is negatively correlated with subjective elapsed time in monkeys performing an oculomotor version of the time production task. When the animals reported two different intervals depending on the instruction, pupil size was correlated with reported timing in each condition but differed for similar timing under different conditions. Given the close correlation between pupil diameter and noradrenergic signaling reported previously, our data indicate that brain states probed by pupil diameter and noradrenergic neuronal activity might modulate subjective passage of time.

\section{Introduction}

Time passes quickly when we enjoy movies but slowly during boring meetings. Daily experience of time is strongly affected by our internal states, such as arousal, attention, and mood (Witt-

\footnotetext{
Received Aug. 10, 2016; revised Sept. 12, 2016; accepted Sept. 18, 2016

Author contributions: T.W.S., J.K., and M.T. designed research; T.W.S. performed research; T.W.S. analyzed data; T.W.S. and M.T. wrote the paper.

This work was supported by the Ministry of Education, Culture, Sports, Science and Technology of Japan, the Ministry of Health, Labour and Welfare of Japan, and the Takeda Science Foundation. Animals were provided by the National Bio-Resource Project. We thank A. Narumi and H. Arime for participating in the early part of the experiments; T. Mori and A. Hironaka for assistance with animal care and surgery; M. Suzuki for administrative help; M. Takei and Y. Hirata for manufacturing equipment; K. Matsuda (Human Informatics Research Institute, AIST) for providing software for the eye tracking system; and all laboratory members for comments and discussions.

The authors declare no competing financial interests.

Correspondence should be addressed to Dr. Masaki Tanaka, Department of Physiology, Hokkaido University School of Medicine, North 15, West 7, Sapporo 060-8638, Japan. E-mail: masaki@med.hokudai.ac.jp.

DOI:10.1523/JNEUROSCI.2533-16.2016

Copyright $\odot 2016$ the authors $\quad 0270-6474 / 16 / 3611331-07 \$ 15.00 / 0$
}

mann, 2009). Many studies have provided empirical support for this. For example, the presentation duration of emotive images is often overestimated in comparison with that of neutral images (Gil and Droit-Volet and Droit-Volet, 2012). Subjects with anxiety tend to report shorter intervals in time reproduction task, whereas those with depression tend to report longer intervals in time production task (Mioni et al., 2016). Although several models of subjective temporal distortion have been proposed (Lake et al., 2016), the exact underlying mechanism remains unclear, partly because neural substrates of temporal processing involve multiple brain systems (Mauk and Buonomano, 2004; Ivry and Schlerf, 2008; Merchant et al., 2013). Therefore, in addition to specific circuits, the roles of global, whole-brain states need to be explored for a comprehensive understanding of temporal processing. In the present study, we examined pupil dynamics in monkeys performing the time production task to probe the brain state and underlying neuromodulatory signals. 
Under constant illumination, pupil diameter is sensitive to various cognitive factors, such as attention, working memory, emotion, and perception (Laeng et al., 2012; Graur and Siegle, 2013; Sirois and Brisson, 2014). For example, Einhäuser et al. (2008) showed that perceptual switch of visual or auditory rivalry was preceded by pupil dilation and that the magnitude of dilation was a significant predictor of the subsequent duration of perceptual stability. Wang et al. (2015) also demonstrated that pupil size correlated with anti-saccade performance in monkeys, suggesting a close link between pupil size and conflict resolution. Simultaneous recordings of neuronal activity and pupil diameter have provided insight into the mechanism underlying these observations. In rodents, pupil size correlates with several aspects of cortical activity, including the variance of membrane potentials, spontaneous firing rates, signal-to-noise ratio of sensory response, and oscillatory states measured by local field potentials (Reimer et al., 2014; McGinley et al., 2015; Vinck et al., 2015). In monkeys, trial-by-trial correlation between pupil size and neuronal firing rate has been reported in the somatosensory cortex (Iriki et al., 1996) as well as in the anterior cingulate cortex (Ebitz and Platt, 2015). These previous observations indicate that pupil diameter reflects different aspects of internal state, which can have a substantial impact on various neuronal computations.

Pupil size also correlates with neuronal activity in the locus ceruleus (Aston-Jones and Cohen, 2005; Murphy et al., 2014; Varazzani et al., 2015; Joshi et al., 2016). Because the locus ceruleus is the major source of noradrenaline (NA) in the brain, pupil diameter has often been viewed as a behavioral index of the activity of the noradrenergic system (Einhäuser et al., 2008; Gilzenrat et al., 2010; Eldar et al., 2013; Kihara et al., 2015; Warren et al., 2016). In addition to its roles in arousal and mood, NA is also important for more specialized cognitive functions, such as attention (Sara and Bouret, 2012), working memory (Arnsten et al., 1988), and behavioral flexibility (McGaughy et al., 2008). In terms of temporal processing, systemic application of a NA reuptake inhibitor or an adrenoceptor agonist altered timing behavior in both humans and rodents (Penney et al., 1996; Rammsayer et al., 2001). In the present study, as a step toward understanding of how NA-related brain states modulate temporal processing, we measured pupil diameter in monkeys performing the self-timed saccade task, an oculomotor version of the time production task. We found that pupil diameter was negatively correlated with trial-by-trial variation in self-timing, suggesting that a transient elevation in NA activity might increase the subjective passage of time. Some of the present results have been reported as an abstract (Suzuki and Tanaka, 2016).

\section{Materials and Methods}

Animal preparation and surgery. Three adult Japanese monkeys (Macaca fuscata, two males, $6-8 \mathrm{~kg}$ ) were used. All experimental protocols were approved in advance by the Hokkaido University Animal Care and Use Committee. The animals were sterilely implanted with head holders and an eye coil in separate surgical procedures under general isoflurane anesthesia. Analgesics (pentazocine and ketoprofen) were administered during each procedure and for a few days after surgery. When fully recovered, the animals were trained on oculomotor tasks. During the training and experimental sessions, animals sat in a primate chair with their heads fixed to the chair in a dark booth. Horizontal and vertical eye position were recorded using the search coil technique (MEL-25, Enzanshi Kogyo).

Visual stimuli and behavioral tasks. Experiments were controlled by a real-time data acquisition system (TEMPO, Reflective Computing). Visual stimuli were presented on a 27 inch LCD monitor (XL2720Z, BenQ, refresh rate: $60-144 \mathrm{~Hz})$ located $46 \mathrm{~cm}$ from the eyes $\left(33 \times 20^{\circ}\right.$ of visual angle). In the self-timed saccade task (see Fig. $1 A$ ), each trial began with the appearance of a fixation point ( $\mathrm{FP}$, blue $0.3^{\circ}-0.5^{\circ}$ square, $8.3 \mathrm{~cd} / \mathrm{m}^{2}$, Experiments 1 and 2) located $6^{\circ}-7^{\circ}$ to the right or left of the screen center. We also presented a gray background $\left(9.4 \mathrm{~cd} / \mathrm{m}^{2}\right.$, either full screen or $66 \times 20^{\circ}$ rectangle) throughout the experiments to avoid excessive pupil dilation. Fixation was detected when eye position remained within $3^{\circ}$ of the FP for $500 \mathrm{~ms}$. After an additional $1200 \mathrm{~ms}$ fixation period, a visual cue (white $0.3^{\circ}-0.5^{\circ}$ square, $24.0 \mathrm{~cd} / \mathrm{m}^{2}$ ) was presented $12^{\circ}-14^{\circ}$ from the FP for $100 \mathrm{~ms}$. Locations of visual stimuli remained unchanged throughout each experimental session. Monkeys were required to generate a memory-guided saccade to the cue location after the predetermined mandatory delay interval following the cue onset. The FP disappeared only after the saccade so that the animals needed to decide saccade timing internally, without any external cue. The mandatory delay period was $1000 \mathrm{~ms}$ for Experiments 1 and 2, but differed depending on the color of the FP in Experiment 3 (see below). Saccades were detected when eye position deviated $>3^{\circ}-5^{\circ}$ from the $\mathrm{FP}$, and trials were aborted if monkeys did not maintain fixation during the fixation period or failed to generate a saccade within $1700 \mathrm{~ms}$ following the visual cue. Each correct trial ended with a delivery of juice reward. Intertrial interval ranged from 3600 to $6000 \mathrm{~ms}$.

All three animals were used for Experiment 1, but only two (Monkeys $\mathrm{B}$ and $\mathrm{F}$ ) were used for Experiments 2 and 3. In Experiment 2, reward size was alternated after every 10 trials $(\sim 0.12$ and $0.24 \mathrm{ml}$ per trial). Because no advanced information about the amount of reward was given in each trial, monkeys would have noticed the block change at the first reward delivery in the new block. Therefore, for the analysis of the time courses of self-timed saccade latency and pupil diameter (see Fig. $3 B, C$ ), we shifted the trial number so that the first trial in each block was always rewarded.

In Experiment 3, two mandatory delay intervals (short or long) were associated with different FP colors $\left(8.1 \mathrm{~cd} / \mathrm{m}^{2}\right)$ and were presented alternately every five consecutive trials. For Monkey B, cyan and pink FPs were associated with short (400-900 ms) and long (700-1300 ms) delay intervals, respectively. For Monkey F, pink and green FPs were associated with short (700-1200 ms) and long (1100-1800 ms) delay intervals, respectively. To exclude possible confounds caused by color difference itself, we chose the pair of FP colors for each monkey based on the results of the fixation task before the training. In this task, a central FP (white $0.3^{\circ}-0.4^{\circ}$ square, $24.0 \mathrm{~cd} / \mathrm{m}^{2}$ ) changed color briefly $(500 \mathrm{~ms})$ during stable fixation. We measured the pupil diameter during the $500 \mathrm{~ms}$ period in five sessions for each monkey, and chose the pair from six equiluminant colors that exhibited no significant difference in pupil size (Monkey B, $-0.01 \pm 0.06$ and $0.02 \pm 0.02$ in $z$-scores for colors assigned to short and long intervals, respectively, paired $t$ test, $p=0.39$; Monkey F, $0.04 \pm 0.04$ and $0.02 \pm 0.08, p=0.53$ ).

We also presented the visually guided saccade task as a control. In this task, a purple FP $\left(0.3^{\circ}-0.5^{\circ}\right.$ circle, $\left.8.1 \mathrm{~cd} / \mathrm{m}^{2}\right)$ was presented at the center of the screen. After a $1700 \mathrm{~ms}$ fixation period, the target appeared $7^{\circ}$ to the left or right. Monkeys were required to make a saccade within $400 \mathrm{~ms}$ to obtain reward. Trials with predictive saccades (reaction time $<70 \mathrm{~ms}$ ) were excluded from further analysis.

Data acquisition and analysis. Pupil diameter was measured using an infrared eye tracking system (iRecHS2, Human Informatics Research Institute, AIST). Eye position and pupil data were digitized and sampled at $1 \mathrm{kHz}$ along with the event timestamps, and were saved in files for the subsequent offline analyses that were performed using MATLAB (The MathWorks). Data from the period between $100 \mathrm{~ms}$ after fixation start and $50 \mathrm{~ms}$ before saccade initiation were examined. Trials with eye blinks or unusual noise were removed. We also excluded trials where pupil size exceeded or fell below the 3.5 SD threshold during the analysis interval ( $500 \mathrm{~ms}$ before cue onset, $0.35 \%$ of trials). Our quantitative analyses were based on the mean pupil diameter during the analysis interval and the latency of self-initiated saccade measured from the cue onset. Trials with inaccurate or goal nondirected saccades $\left(>5^{\circ}\right.$ from cue location, $\left.9.9 \%\right)$ were excluded from the analysis. Data from early saccades $(<60 \%$ of the mandatory interval) were analyzed separately from the remaining trials (see Fig. 1B; Results). For analysis within each session, raw pupil data (a.u.) were used. For analysis across sessions, data for individual trials 
A

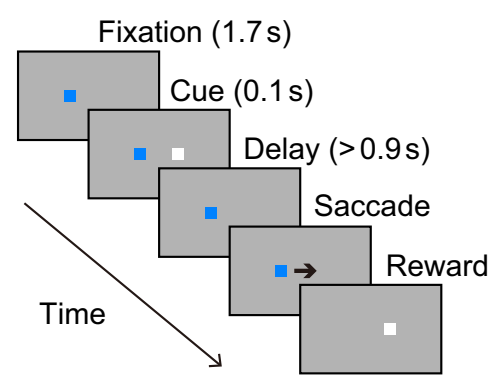

B

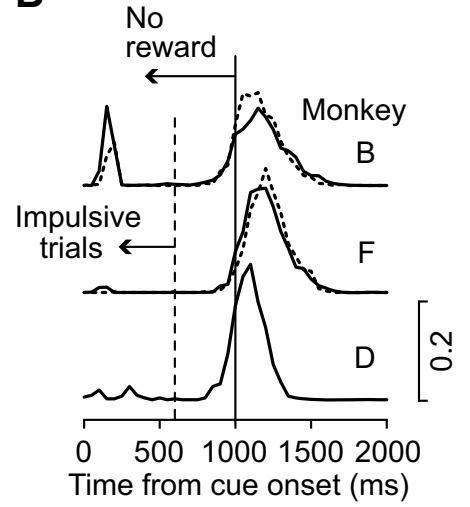

Figure 1. Behavioral paradigm and distributions of saccade latency. $\boldsymbol{A}$, Temporal structure of the self-timed saccade task. Monkeys were trained to generate a saccade after a mandatory delay interval following the cue. $\boldsymbol{B}$, Distributions of saccade latencies. Solid lines indicate data for 3175 (top, Monkey B), 1831 (middle, Monkey F), and 798 (bottom, Monkey D) self-timed saccades in Experiment 1. Broken lines indicate data from five probe sessions (see Materials and Methods), in which the time between the start of fixation and cue onset was 1400, 1700, or $2000 \mathrm{~ms}$, selected randomly ( $n=1343$ and $n=922$ for Monkeys $B$ and $F$, respectively). Histograms were computed for 50 ms bins. Vertical dotted line indicates the latency criterion ( $\geq 600 \mathrm{~ms}$ ) for the main analysis. Most of the early impulsive saccades occurred within a few hundred milliseconds following the cue and constituted a discrete trial population.

were converted to $z$-scores for each session. The effects of reward size (Experiment 2) were assessed by computing a modulation index defined as $(\mathrm{R} 1-\mathrm{R} 2) /(\mathrm{R} 1+\mathrm{R} 2)$ where $\mathrm{R} 1$ and $\mathrm{R} 2$ indicate the data for different amounts of reward. For statistical comparisons, we used either unpaired or paired $t$ tests. Details are described in the relevant text in Results.

\section{Results}

In the self-timed saccade task, the animals obtained reward for a self-initiated memory-guided saccade that was generated $1000-$ $1700 \mathrm{~ms}$ following cue onset (Fig. $1 A$ ). Figure $1 B$ shows the distribution of saccade latency in 25 experimental sessions (10 sessions for Monkeys B and F, five sessions for Monkey D; solid traces, $n=3175,1831$, and 798 for Monkeys B, F, and D, respectively). Most saccades were generated $>1000 \mathrm{~ms}$ after the cue onset, and those with shorter latencies constituted $<30 \%$ of trials. Saccades with a latency $>1700 \mathrm{~ms}$ were vanishingly rare $(<0.1 \%)$. For all three animals, early error trials with saccade latencies $<600 \mathrm{~ms}$ (Fig. $1 B$, vertical dashed line) constituted a distinct population. We regarded these saccades as "impulsive" and examined them separately (see below).

During the training sessions, time from fixation to cue onset varied from trial to trial but was constant during the experimental sessions (1700 ms; Fig. 1A). To ensure that monkeys determined saccade timing based on the elapsed time from the cue appearance rather than fixation start, we also interleaved probe sessions, in which the time between fixation start and cue onset was randomly chosen from a set of 1400, 1700, and $2000 \mathrm{~ms}$ (Fig. 1B, dotted traces). If the animals measured the elapsed time from the start of fixation, saccade latency measured from the cue appearance would be more variable in the probe sessions. However, for nonimpulsive trials (i.e., latency $\geq 600 \mathrm{~ms}$ ), the variance of latency in the probe sessions was less than that in the experimental sessions $\left(1.83 \times 10^{4}\right.$ vs $2.69 \times 10^{4} \mathrm{~ms}^{2}$ and $1.60 \times 10^{4}$ vs $1.84 \times$ $10^{4} \mathrm{~ms}^{2}$ for Monkeys B and F, respectively; $F$ test, $p<0.01$ ), indicating that the animals determined saccade timing relative to the cue appearance.

\section{Experiment 1: relationship between pupil diameter and saccade latency}

Figure $2 A$ shows the time courses of pupil diameter in a single experimental session in Monkey F. For this figure, trials were

divided equally into three groups according to saccade latency, then the mean $( \pm \mathrm{SE})$ pupil diameter for the early and late saccade groups are plotted as red and blue traces, respectively. Pupil constricted shortly after the start of fixation (1700 ms before cue presentation) and then dilated gradually. The time course of pupil dilation differed between the groups, showing a greater pupil size at the time of cue appearance (Fig. $2 A$, vertical solid line) for the early than the late saccade groups, even though self-timed saccades occurred $\sim 1000 \mathrm{~ms}$ later (Fig. $1 B)$. To quantify this finding in multiple experiments, we measured pupil size during the $500 \mathrm{~ms}$ before cue onset (Fig. 2A, upper bracket) and calculated $z$-score for each trial. Figure $2 B$ compares the data between the early and late saccade groups for 25 experimental sessions, showing that pupil size was significantly greater for the early saccade groups than the late saccade groups (one-tailed paired $t$ test, $p<10^{-4}$ ). These results were consistent across monkeys.

We next assessed the correlation between pupil size and selftimed saccade latency. Because saccade latency and pupil size were highly variable, trial-by-trial correlation was only slight, averaging $-0.10 \pm 0.08(\mathrm{SD}, n=25)$, although it was statistically different from zero (one-sample $t$ test, $p<10^{-5}$ ). To examine the underlying correlation, Pearson's correlation coefficients were computed after 10 trial moving averages along the order of the pupil size (Fig. 2C, inset, red line). The distribution of correlation coefficients was also statistically different from zero (mean $\pm \mathrm{SD}=-0.24 \pm 0.22, p<10^{-4}$; Fig. $2 C$ ).

To further elucidate the relationship between pupil size and self-timed saccade latency, the data were divided into 10 groups according to the pupil size for each experimental session and were averaged across sessions. Figure $2 D$ shows the means ( $\pm 95 \% \mathrm{CI}$ ) of latency modulation (i.e., deviation from the mean in each session) plotted as a function of pupil size. Although we found that the pupil size and self-timed saccade latency were significantly correlated (Spearman's rank correlation coefficient $r_{\mathrm{s}}=$ $-0.94, p<10^{-5}$; Fig. $2 D$, red data points), the pupil size and visually guided saccade latency were not $\left(r_{\mathrm{s}}=-0.41, p=0.25\right.$; blue points). Thus, greater pupil size before the visual cue accompanied shorter saccade latency in the self-timing task, but these effects were unlikely to be solely attributed to the facilitation of saccade generation.

The results in Figure $2 D$ indicate that the pupil diameter is a good predictor of saccade latency in the self-timed task but not in the visually guided task. However, the significant correlation for self-timed saccades could be due to their greater latency variability than visually guided saccades. To examine this, we selected a subset of self-timed trials with a similar range of latency variability to visually guided trials, and performed the same analysis as in Figure 2D. Because the latency modulation across 10 pupil size groups in the visually guided trials (i.e., variation along the vertical axis in Fig. 2D) ranged from $-30.9 \mathrm{~ms}$ to $38.1 \mathrm{~ms}$, we extracted self-timed trials with latencies within mean $\pm 38 \mathrm{~ms}$ for each session. When we performed the same analysis as in Figure $2 D$ on the subsampled data, we failed to find significant correlation between pupil size and self-timed saccade latency 
$\left(r_{\mathrm{s}}=-0.62, p=0.06\right)$. Therefore, it is possible that visually guided saccades with similar latency variability to self-timed saccades might uncover strong correlation between latency and pupil size as reported previously (Jainta et al., 2011).

Early self-timed saccades might also result from increased impulsivity, which could modulate pupil diameter (Serfas et al., 2014). To examine this, pupil diameter in trials with impulsive saccades (latency $<600$ ms; Fig. 1B) was compared with that in the remaining trials. If the modulation of self-timed saccade latency was attributed to the level of impulsivity, the impulsive saccades with very short latency must accompany large pupil diameter. However, we found no significant difference in pupil diameter between the trials $(-0.05 \pm 0.26$ vs $0.01 \pm 0.03$ in $z$-scores for impulsive and the other trials, respectively, $n=15$ sessions with more than five impulsive saccades, paired $t$ test, $p=$ $0.44)$. Furthermore, when we divided the data of nonimpulsive trials into three groups according to self-timed saccade latency, the pupil diameter for the early, middle, and late saccade groups averaged $0.10 \pm 0.07(\mathrm{SD}),-0.03 \pm 0.10$ and $-0.05 \pm 0.12$, respectively, and the pupil diameter for the early saccade group was significantly greater than that for the impulsive saccades (one-tailed paired $t$ test, $p<0.05)$. Thus, our results were not merely due to the level of impulsivity.

\section{Experiment 2: effects of reward size}

So far, we have examined correlation between the naturally occurring fluctuations of pupil size and saccade latency. We also attempted to modulate pupil diameter systematically by changing the amount of reward and examining its correlation with self-timed saccade latency. In Experiment 2, the amount of reward was alternated every 10 trials (Reward $\times 1$ and $\times 2$ conditions). Figure $3 A$ shows the time courses of pupil size in a single experimental session in Monkey B, with a clear difference between the conditions.

We performed six experimental sessions in each of two monkeys (Monkeys B and F). The modulations of saccade latency and pupil diameter during the transition of reward size are shown in Figure 3B. For this analysis, because the animals were unable to notice the block change unless they obtained reward in a new block, we shifted the trial number so that the first trial in each block was always rewarded (i.e., saccade latency was in the range from 1000 to $1700 \mathrm{~ms}$ ). The data show that both the pupil size and saccade latency exhibited strong modulation but in opposite directions. Spearman's rank correlation coefficients computed for the time course of pupil size and saccade latency in individual sessions averaged $-0.28 \pm$ 0.23 (SD, $n=12$ ), which differed significantly from zero (onesample $t$ test, $p<10^{-2}$ ). When the data for different blocks were analyzed separately, rank correlation coefficients averaged $0.02 \pm 0.35(p=0.85)$ and $-0.33 \pm 0.33\left(p<10^{-2}\right)$ for Reward $\times 1$ and $\times 2$ blocks, respectively.
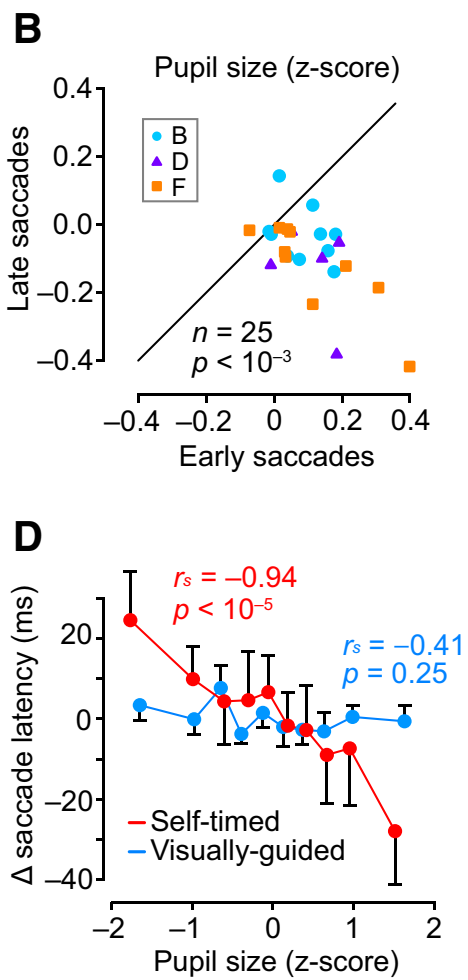

Figure 2. Correlation between pupil size and saccade latency (Experiment 1). $\boldsymbol{A}$, Time courses of pupil diameter during the self-timed task in an example session in Monkey F. Trials were divided into three equal groups according to saccade latency. Red ue traces represent the mean ( \pm SE) pupil size for the earliest and latest saccade groups, respectively. Top bracket represent

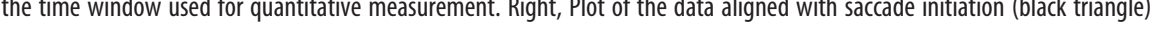
see Results). Inset, Representative session (same as $\boldsymbol{A}$ ). $\boldsymbol{D}$, Relationship between pupil size and modulation of latency (shifted by the mean) of self-timed (red) and visually guided (blue) saccades. Error bars indicate $\pm 95 \% \mathrm{Cl}$.

Although pupil diameter and saccade latency significantly correlated during the Reward $\times 2$ block, their time courses were somewhat different: saccade latency greatly decreased during the initial few trials and quickly returned toward the mean, whereas pupil diameter stayed high throughout the block. Thus, the reduction of saccade latency during the double reward condition had transient and sustained components, whereas the modulation of pupil diameter had only the latter. These results suggest that there might exist two different reward-related neural mechanisms: one that operates transiently and regulates only saccade latency and the other continuously alters both saccade latency and pupil diameter.

For comparison across sessions, we also computed the modulation indices based on the first to ninth trials in each block for both the pupil size and saccade latency (see Materials and Methods). Figure $3 C$ shows that the modulation indices for pupil size and saccade latency were negatively correlated $\left(r_{\mathrm{s}}=-0.85, n=\right.$ $12, p<10^{-3}$ ), indicating that greater modulations in pupil size were associated with greater modulations of saccade latency.

\section{Experiment 3: relative versus absolute timing}

Finally, we asked whether pupil size was correlated with either the fluctuation of individual saccade timing relative to the behavioral goal, or the absolute saccade latency measured from the cue appearance regardless of behavioral condition. To discriminate these possibilities, monkeys were trained to report two different time intervals (short or long) indicated by the color of the FP (see Materials and Methods). Then, we compared the pupil diameter 
A

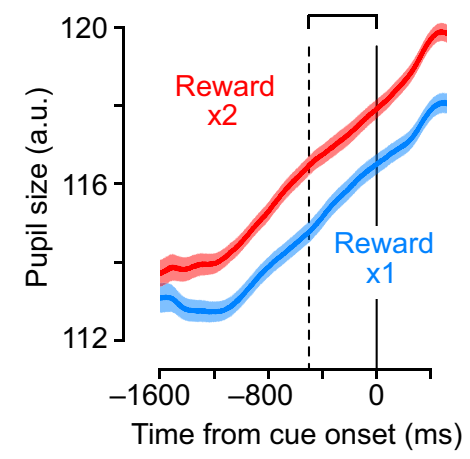

C

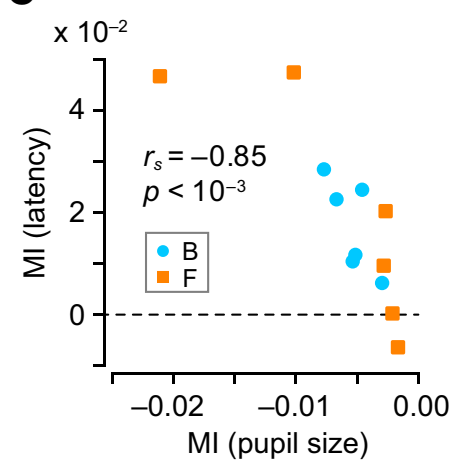

B
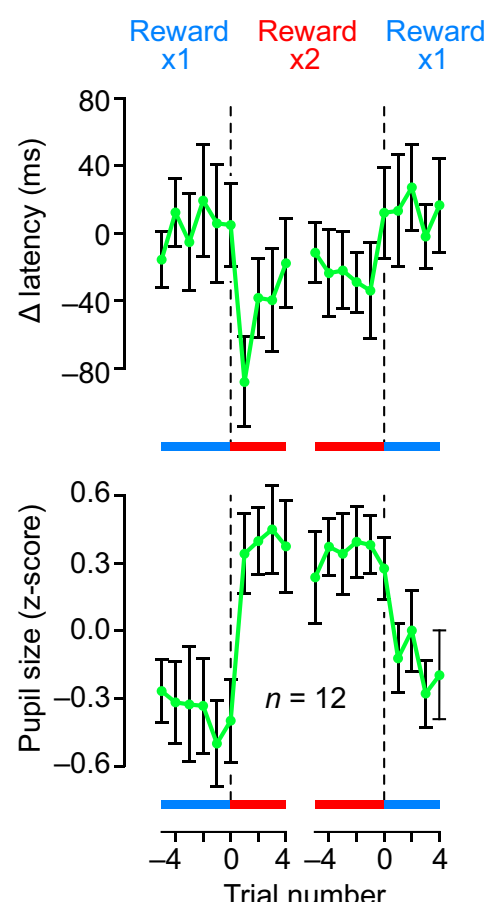

relative to block change

Figure 3. Pupil size and saccade latency covaried with the amount of reward (Experiment 2). $A$, Time courses of pupil size (mean \pm SE) during an example session in Monkey B. Different colors represent different reward schedules. $\boldsymbol{B}$, Changes in saccade latency (top) and pupil size (bottom) during the transition between blocks with different reward amounts. For each session, we computed median value in each trial number. Data points represent mean $\pm 95 \% \mathrm{Cl}$ across 12 sessions. C, Correlation between Modulation Indices (Mls) computed for pupil diameter and saccade latency.

A

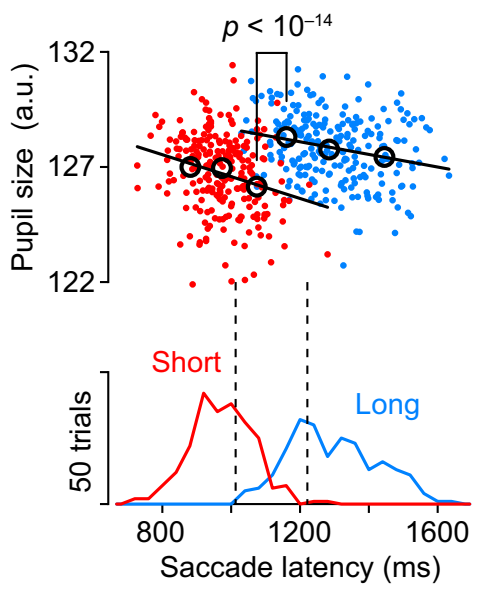

B

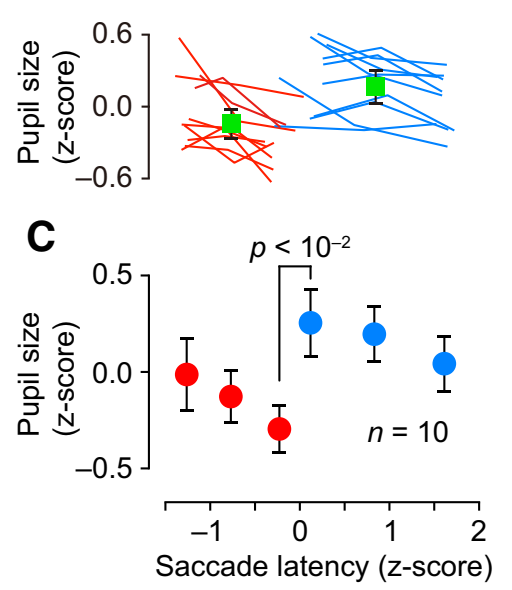

Figure 4. Comparison between different mandatory delay intervals (Experiment 3). $\boldsymbol{A}$, Example session in Monkey $\mathrm{F}$. Scatter plot shows data from individual trials. Red and blue represent trials with short or long instructions, respectively. Regression lines (black) were computed for each condition. Black circles represent the means for each of the early, medium, and late saccade groups. Bottom, Saccade latency distribution for each condition. Vertical dashed lines indicate lower and upper limits of saccade latency for $\$ 3$ and L1 groups, respectively. $\boldsymbol{B}$, Pupil size and saccade latency for the three saccade latency groups in individual sessions. Red and blue lines indicate short and long conditions, respectively. Green square represents the mean $( \pm 95 \% \mathrm{Cl})$ for the entirety of each condition. Although overall pupil size for long condition was statistically larger than that for short condition (one-tailed paired $t$ test, $p=0.03$ ), this difference was less consistent across sessions compared with the difference between $\mathrm{S} 3$ and L1. C, Summary of multiple experiments in two monkeys. Data points indicate the mean $( \pm 95 \% \mathrm{Cl})$ pupil size and saccade latency for each of the three saccade latency groups.

in trials with similar latency but under different instructions (i.e., those with similar absolute, but different relative latencies). Figure $4 A$ shows the data from a single experimental session in Monkey F. This animal was trained to wait $700 \mathrm{~ms}$ for a pink FP and $1100 \mathrm{~ms}$ for a cyan FP. When we looked at the scatter plot and regression lines in Figure $4 A$, we again found a negative correlation between the pupil size and saccade latency for each mandatory delay interval (regression slopes: -0.0048 and -0.0027 for the short and long intervals, respectively, $p<10^{-3}$ ). However, when we compared the data between the two conditions, pupil diameter was generally greater for the long delay interval, even for trials with similar latencies. To quantify this, the data for each condition were divided into three groups according to saccade latency (Fig. 4A, black circles). Although saccade latency for the latest group in the short condition (S3) was shorter than that for the earliest group in the long condition (L1), the pupil size for S3 was significantly smaller than that for L1 (one-tailed unpaired $t$ test, $p<10^{-15}$ ). We conducted this analysis for each of 10 sessions (four and six sessions in Monkeys B and F, respectively; Fig. 4B), and found that pupil size for S3 was significantly smaller than that for L1 in 7 sessions $\left(p<10^{-3}\right)$. In the population, Figure $4 C$ summarizes the means $( \pm 95 \% \mathrm{CI})$ across sessions and shows that the pupil size was statistically larger for L1 than S3 (one-tailed paired $t$ test, $n=10$, $p<10^{-2}$ ), whereas saccade latency was longer for $\mathrm{L} 1$ than $\mathrm{S} 3(p<0.01)$. Thus, the pupil size was negatively correlated with the trial-by-trial fluctuation of saccade latency in a given condition but did not reflect absolute saccade timing under different behavioral goals.

\section{Discussion}

In this study, we found that pupil size was negatively correlated with saccade latency in the oculomotor version of the time production task (Experiment 1). Although a previous study showed that pupil dilation was linked to the facilitation of saccades (Jainta et al., 2011), the promotion of motor execution might not account for our results because we failed to find a significant correlation for visually guided saccades under our experimental condition (Fig. 2D). We also found that reward amounts altered the pupil size and selftimed saccade latency in opposite directions (Experiment 2) and showed a strong correlation between the magnitudes of modulation (Fig. 3C), further supporting 
the close link between pupil diameter and self-timing. Furthermore, in the animals trained to produce two different intervals depending on the instruction, pupil size correlated negatively with trial-by-trial variation of saccade latency in each condition; however, the pupil diameter differed between conditions even for similar saccade latencies (Experiment 3; Fig. 4). Thus, the brain states indexed by pupil size seemed to bias the trial-by-trial latency of self-timing in a given condition.

\section{Relationship between pupil-linked brain states and temporal processing}

We used pupillary measurement to probe the internal brain state and the underlying neuromodulatory signaling. We will refer to the internal states as "pupil-linked brain states," corresponding to the term "pupil-linked brain systems" used in a previous study (Kloosterman et al., 2015). In our self-timing task, earlier saccades might occur merely as a result of an inability to withhold saccades resulting from increased impulsivity (Wittmann and Paulus, 2008; Rajala et al., 2015). However, shorter-latency $(<600 \mathrm{~ms}$; Fig. 1B), erroneous impulsive saccades toward the cue did not accompany larger pupil diameter, suggesting that the correlation between pupil size and self-timed saccade latency may not be solely due to the level of impulsivity. Instead, the present results indicate that pupil-linked brain states might influence neuronal activity related to the monitoring of elapsed time.

Previous studies have reported a gradual ramping-up of neuronal activity in the cerebral cortex (Maimon and Assad, 2006; Mita et al., 2009; Merchant et al., 2011; Murakami et al., 2014; Parker et al., 2014; Xu et al., 2014; Jazayeri and Shadlen, 2015), thalamus (Tanaka, 2007), basal ganglia (Lee and Assad, 2003; Turner and Anderson, 2005), and cerebellum (Ashmore and Sommer, 2013) in animals performing a time production task. Because perturbation of these activities alters self-timing (Tanaka, 2006; Kunimatsu and Tanaka, 2012; Xu et al., 2014), the time course of the ramping activity might determine movement timing. Such activity appears to be consistent with the accumulation-to-threshold model of decision making in which a higher accumulation rate results in earlier reports of passage of time, or shorter latencies of self-timed movements in time production tasks (Maimon and Assad, 2006). Because pupil diameter is known to correlate with visual response gain (Reimer et al., 2014; Vinck et al., 2015), the brain states with larger pupil diameter would be associated with higher gain, and thus faster accumulation rate, of neurons with ramping-up activity, leading to speed up of subjective passage of time, thereby resulting in shorter self-timed saccade latencies.

On the other hand, another prevailing model of interval timing assumes different neural populations for specific intervals (Heron et al., 2012; Hayashi et al., 2015). Although we do not know exactly how gain enhancement of duration-specific elements can bias temporal production, integration of multiple elements into a single ramping-up of activity (Murakami et al., 2014) might be a possible way to explain our results.

\section{Effects of noradrenaline on subjective passage of time}

Given the strong correlation with pupil diameter (Aston-Jones and Cohen, 2005; Murphy et al., 2014; Varazzani et al., 2015; Joshi et al., 2016), the modulation of NA signaling might underlie the alteration of temporal processing. Indeed, Rammsayer et al. (2001) demonstrated that systemic administration of an NA reuptake inhibitor improves performance in a duration discrimination task. NA modulates neuronal excitability and the gain of response to synaptic input in different cortical and subcortical areas (Waterhouse et al., 1980; McCormick, 1989; Carr et al., 2007; Samuels and Szabadi, 2008; Zhang et al., 2013; Ohta et al., 2016). Furthermore, electrical stimulation of locus ceruleus elevates cortical excitability (Marzo et al., 2014). In addition to arousal and attentional control, NA and related substances greatly alter neuronal information coding and affect performance in a variety of cognitive tasks (Arnsten et al., 1988; Matsumura et al., 1990; Sawaguchi et al., 1990). In particular, Wang et al. (2011) showed that iontophoretic application of an $\alpha 2$ adrenoceptor agonist dramatically enhanced sustained neuronal firing in the prefrontal cortex during a working memory task. Thus, the available data support the hypothesis that NA modulates temporal processing in such a way that higher NA signaling promotes the subjective passage of time. Because NA is a key modulator of attention and affective states (Berridge and Waterhouse, 2003), NA might mediate the influence of these states on our daily experience of time. Future studies, using more direct approaches such as pharmacological or optogenetic manipulation of neuronal activity, will elucidate the detailed mechanism.

\section{References}

Arnsten AF, Cai JX, Goldman-Rakic PS (1988) The alpha-2 adrenergic agonist guanfacine improves memory in aged monkeys without sedative or hypotensive side effects: evidence for alpha-2 receptor subtypes. J Neurosci 8:4287-4298. Medline

Ashmore RC, Sommer MA (2013) Delay activity of saccade-related neurons in the caudal dentate nucleus of the macaque cerebellum. J Neurophysiol 109:2129-2144. CrossRef Medline

Aston-Jones G, Cohen JD (2005) An integrative theory of locus coeruleusnorepinephrine function: adaptive gain and optimal performance. Annu Rev Neurosci 28:403-450. CrossRef Medline

Berridge CW, Waterhouse BD (2003) The locus coeruleus-noradrenergic system: modulation of behavioral state and state-dependent cognitive processes. Brain Res Brain Res Rev 42:33-84. CrossRef Medline

Carr DB, Andrews GD, Glen WB, Lavin A (2007) Alpha2-noradrenergic receptors activation enhances excitability and synaptic integration in rat prefrontal cortex pyramidal neurons via inhibition of HCN currents. J Physiol 584:437-450. CrossRef Medline

Ebitz RB, Platt ML (2015) Neuronal activity in primate dorsal anterior cingulate cortex signals task conflict and predicts adjustments in pupillinked arousal. Neuron 85:628-640. CrossRef Medline

Einhäuser W, Stout J, Koch C, Carter O (2008) Pupil dilation reflects perceptual selection and predicts subsequent stability in perceptual rivalry. Proc Natl Acad Sci U S A 105:1704-1709. CrossRef Medline

Eldar E, Cohen JD, Niv Y (2013) The effects of neural gain on attention and learning. Nat Neurosci 16:1146-1153. CrossRef Medline

Gil S, Droit-Volet S (2012) Emotional time distortions: the fundamental role of arousal. Cogn Emot 26:847-862. CrossRef Medline

Gilzenrat MS, Nieuwenhuis S, Jepma M, Cohen JD (2010) Pupil diameter tracks changes in control state predicted by the adaptive gain theory of locus coeruleus function. Cogn Affect Behav Neurosci 10:252-269. CrossRef Medline

Graur S, Siegle G (2013) Pupillary motility: bringing neuroscience to the psychiatry clinic of the future. Curr Neurol Neurosci Rep 13:365. CrossRef Medline

Hayashi MJ, Ditye T, Harada T, Hashiguchi M, Sadato N, Carlson S, Walsh V, Kanai R (2015) Time adaptation shows duration selectivity in the human parietal cortex. PLoS Biol 13:e1002262. CrossRef Medline

Heron J, Aaen-Stockdale C, Hotchkiss J, Roach NW, McGraw PV, Whitaker D (2012) Duration channels mediate human time perception. Proc Biol Sci 279:690-698. CrossRef Medline

Iriki A, Tanaka M, Iwamura Y (1996) Attention-induced neuronal activity in the monkey somatosensory cortex revealed by pupillometrics. Neurosci Res 25:173-181. CrossRef Medline

Ivry RB, Schlerf JE (2008) Dedicated and intrinsic models of time perception. Trends Cogn Sci 12:273-280. CrossRef Medline

Jainta S, Vernet M, Yang Q, Kapoula Z (2011) The pupil reflects motor preparation for saccades: even before the eye starts to move. Front Hum Neurosci 5:97. CrossRef Medline 
Jazayeri M, Shadlen MN (2015) A neural mechanism for sensing and reproducing a time interval. Curr Biol 25:2599-2609. CrossRef Medline

Joshi S, Li Y, Kalwani RM, Gold JI (2016) Relationships between pupil diameter and neuronal activity in the locus coeruleus, colliculi, and cingulate cortex. Neuron 89:221-234. CrossRef Medline

Kihara K, Takeuchi T, Yoshimoto S, Kondo HM, Kawahara JI (2015) Pupillometric evidence for the locus coeruleus-noradrenaline system facilitating attentional processing of action-triggered visual stimuli. Front Psychol 6:827. CrossRef Medline

Kloosterman NA, Meindertsma T, van Loon AM, Lamme VA, Bonneh YS, Donner TH (2015) Pupil size tracks perceptual content and surprise. Eur J Neurosci 41:1068-1078. CrossRef Medline

Kunimatsu J, Tanaka M (2012) Alteration of the timing of self-initiated but not reactive saccades by electrical stimulation in the supplementary eye field. Eur J Neurosci 36:3258-3268. CrossRef Medline

Laeng B, Sirois S, Gredebäck G (2012) Pupillometry: a window to the preconscious? Perspect Psychol Sci 7:18-27. CrossRef Medline

Lake JI, LaBar KS, Meck WH (2016) Emotional modulation of interval timing and time perception. Neurosci Biobehav Rev 64:403-420. CrossRef Medline

Lee IH, Assad JA (2003) Putaminal activity for simple reactions or selftimed movements. J Neurophysiol 89:2528-2537. CrossRef Medline

Maimon G, Assad JA (2006) A cognitive signal for the proactive timing of action in macaque LIP. Nat Neurosci 9:948-955. CrossRef Medline

Marzo A, Totah NK, Neves RM, Logothetis NK, Eschenko O (2014) Unilateral electrical stimulation of rat locus coeruleus elicits bilateral response of norepinephrine neurons and sustained activation of medial prefrontal cortex. J Neurophysiol 111:2570-2588. CrossRef Medline

Matsumura M, Sawaguchi T, Kubota K (1990) Modulation of neuronal activities by iontophoretically applied catecholamines and acetylcholine in the primate motor cortex during a visual reaction-time task. Neurosci Res 8:138-145. CrossRef Medline

Mauk MD, Buonomano DV (2004) The neural basis of temporal processing. Annu Rev Neurosci 27:307-340. CrossRef Medline

McCormick DA (1989) Cholinergic and noradrenergic modulation of thalamocortical processing. Trends Neurosci 12:215-221. CrossRef Medline

McGaughy J, Ross RS, Eichenbaum H (2008) Noradrenergic, but not cholinergic, deafferentation of prefrontal cortex impairs attentional setshifting. Neuroscience 153:63-71. CrossRef Medline

McGinley MJ, David SV, McCormick DA (2015) Cortical membrane potential signature of optimal states for sensory signal detection. Neuron 87:179-192. CrossRef Medline

Merchant H, Zarco W, Pérez O, Prado L, Bartolo R (2011) Measuring time with different neural chronometers during a synchronization-continuation task. Proc Natl Acad Sci U S A 108:19784-19789. CrossRef Medline

Merchant H, Harrington DL, Meck WH (2013) Neural basis of the perception and estimation of time. Annu Rev Neurosci 36:313-336. CrossRef Medline

Mioni G, Stablum F, Prunetti E, Grondin S (2016) Time perception in anxious and depressed patients: a comparison between time reproduction and time production tasks. J Affect Disord 196:154-163. CrossRef Medline

Mita A, Mushiake H, Shima K, Matsuzaka Y, Tanji J (2009) Interval time coding by neurons in the presupplementary and supplementary motor areas. Nat Neurosci 12:502-507. CrossRef Medline

Murakami M, Vicente MI, Costa GM, Mainen ZF (2014) Neural antecedents of self-initiated actions in secondary motor cortex. Nat Neurosci 17:1574-1582. CrossRef Medline

Murphy PR, O'Connell RG, O'Sullivan M, Robertson IH, Balsters JH (2014) Pupil diameter covaries with BOLD activity in human locus coeruleus. Hum Brain Mapp 35:4140-4154. CrossRef Medline

Ohta H, Kohno Y, Arake M, Tamura R, Yukawa S, Sato Y, Morimoto Y, Nishida Y, Yawo H (2016) Adrenergic receptor-mediated modulation of striatal firing patterns. Neurosci Res. Advance online publication. Retrieved Jun. 7, 2016. doi: 10.1016/j.neures.2016.05.004. CrossRef Medline

Parker KL, Chen KH, Kingyon JR, Cavanagh JF, Narayanan NS (2014) D1dependent $4 \mathrm{~Hz}$ oscillations and ramping activity in rodent medial frontal cortex during interval timing. J Neurosci 34:16774-16783. CrossRef Medline

Penney TB, Holder MD, Meck WH (1996) Clonidine-induced antagonism of norepinephrine modulates the attentional processes involved in peakinterval timing. Exp Clin Psychopharmacol 4:82-92. CrossRef

Rajala AZ, Jenison RL, Populin LC (2015) Decision making: effects of methylphenidate on temporal discounting in nonhuman primates. J Neurophysiol 114:70-79. CrossRef Medline

Rammsayer TH, Hennig J, Haag A, Lange N (2001) Effects of noradrenergic activity on temporal information processing in humans. Q J Exp Psychol B 54:247-258. CrossRef Medline

Reimer J, Froudarakis E, Cadwell CR, Yatsenko D, Denfield GH, Tolias AS (2014) Pupil fluctuations track fast switching of cortical states during quiet wakefulness. Neuron 84:355-362. CrossRef Medline

Samuels ER, Szabadi E (2008) Functional neuroanatomy of the noradrenergic locus coeruleus: its roles in the regulation of arousal and autonomic function. I. Principles of functional organisation. Curr Neuropharmacol 6:235-253. CrossRef Medline

Sara SJ, Bouret S (2012) Orienting and reorienting: the locus coeruleus mediates cognition through arousal. Neuron 76:130-141. CrossRef Medline

Sawaguchi T, Matsumura M, Kubota K (1990) Catecholaminergic effects on neuronal activity related to a delayed response task in monkey prefrontal cortex. J Neurophysiol 63:1385-1400. Medline

Serfas BG, Büttner OB, Florack A (2014) Eyes wide shopped: shopping situations trigger arousal in impulsive buyers. PLoS One 9:e114593. CrossRef Medline

Sirois S, Brisson J (2014) Pupillometry. Wiley Interdiscip Rev Cogn Sci 5:679-692. CrossRef Medline

Suzuki T, Tanaka M (2016) Correlation between pupil size and subjective passage of time in monkeys. J Physiol Sci 66 [Suppl]:S90.

Tanaka M (2006) Inactivation of the central thalamus delays self-timed saccades. Nat Neurosci 9:20-22. CrossRef Medline

Tanaka M (2007) Cognitive signals in the primate motor thalamus predict saccade timing. J Neurosci 27:12109-12118. CrossRef Medline

Turner RS, Anderson ME (2005) Context-dependent modulation of movement-related discharge in the primate globus pallidus. J Neurosci 25:2965-2976. CrossRef Medline

Varazzani C, San-Galli A, Gilardeau S, Bouret S (2015) Noradrenaline and dopamine neurons in the reward/effort trade-off: a direct electrophysiological comparison in behaving monkeys. J Neurosci 35:7866-7877. CrossRef Medline

Vinck M, Batista-Brito R, Knoblich U, Cardin JA (2015) Arousal and locomotion make distinct contributions to cortical activity patterns and visual encoding. Neuron 86:740-754. CrossRef Medline

Wang CA, Brien DC, Munoz DP (2015) Pupil size reveals preparatory processes in the generation of pro-saccades and anti-saccades. Eur J Neurosci 41:1102-1110. CrossRef Medline

Wang M, Gamo NJ, Yang Y, Jin LE, Wang XJ, Laubach M, Mazer JA, Lee D, Arnsten AF (2011) Neuronal basis of age-related working memory decline. Nature 476:210-213. CrossRef Medline

Warren CM, Eldar E, van den Brink RL, Tona KD, van der Wee NJ, Giltay EJ, van Noorden MS, Bosch JA, Wilson RC, Cohen JD, Nieuwenhuis S (2016) Catecholamine-mediated increases in gain enhance the precision of cortical representations. J Neurosci 36:5699-5708. CrossRef Medline

Waterhouse BD, Moises HC, Woodward DJ (1980) Noradrenergic modulation of somatosensory cortical neuronal responses to iontophoretically applied putative neurotransmitters. Exp Neurol 69:30-49. CrossRef Medline

Wittmann M (2009) The inner experience of time. Philos Trans R Soc Lond B Biol Sci 364:1955-1967. CrossRef Medline

Wittmann M, Paulus MP (2008) Decision making, impulsivity and time perception. Trends Cogn Sci 12:7-12. CrossRef Medline

Xu M, Zhang SY, Dan Y, Poo MM (2014) Representation of interval timing by temporally scalable firing patterns in rat prefrontal cortex. Proc Natl Acad Sci U S A 111:480-485. CrossRef Medline

Zhang Z, Cordeiro Matos S, Jego S, Adamantidis A, Séguéla P (2013) Norepinephrine drives persistent activity in prefrontal cortex via synergistic $\alpha 1$ and $\alpha 2$ adrenoceptors. PLoS One 8:e66122. CrossRef Medline 